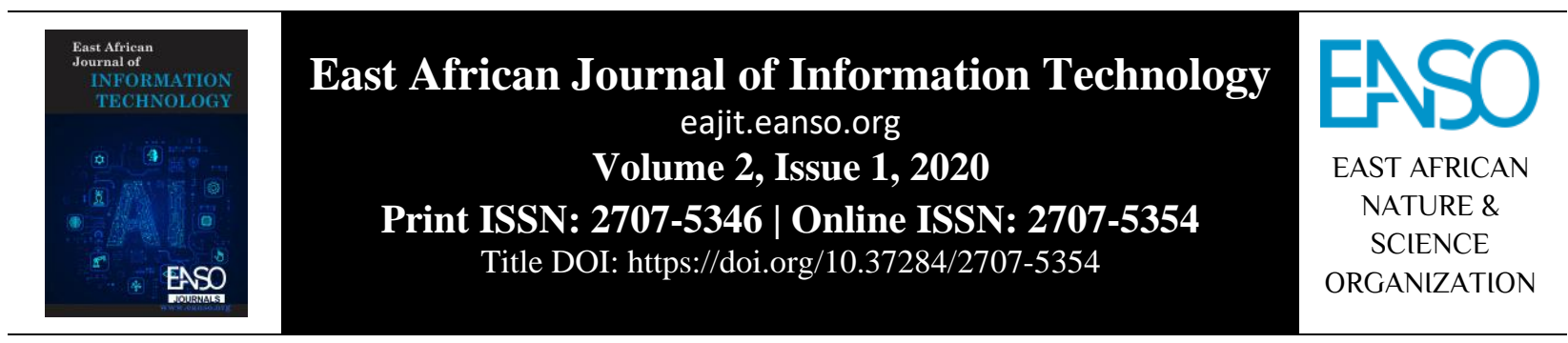

Original Article

\title{
Information and Communications Technology Integration and Performance of Tertiary Institutions in Nairobi County, Kenya
}

\author{
Joy Jerop Kibor* \& Dr. Joshua Tumuti \\ School of Business, Kenyatta University, P. O. Box 43844-00100, Nairobi, Kenya. \\ *Author for correspondence email: joycheropk@gmail.com.
}

Article DOI: https://doi.org/10.37284/eajit.2.1.119

Article history:

Received: 19 Feb 2020

Accepted: 26 Feb 2020

Published: 2 Mar 2020

Keywords:

ICT infrastructure, ICT proficiency, Student Performance, Tertiary Institutions

\begin{abstract}
ICT infrastructure and ICT proficiency have become essential components of higher education for both learners and instructors. This study examined the effect of ICT infrastructure and ICT proficiency on the performance of tertiary institutions in Nairobi County. A simple random sampling method was used to select the respondents. A sample size of 60 respondents was drawn from the ICT specialists employed in the tertiary institutions. Data was collected using questionnaires and the internal reliability analysis showed Cronbach's alpha value of 0.83 . Results findings established that ICT infrastructure and ICT proficiency resulted in better performance of tertiary institutions. The study concluded that ICT infrastructure and ICT proficiency affect the performance of tertiary institutions positively. A recommendation is that tertiary institutions should integrate the use of ICT in different aspects of learning to enhance performance.
\end{abstract}

\section{APA CITATION}

Kibor, J., \& Tumuti, J. (2020). Information and Communications Technology Integration and Performance of Tertiary Institutions in Nairobi County, Kenya. East African Journal of Information Technology, 2(1), 1-7. https://doi.org/10.37284/eajit.2.1.119

\section{CHICAGO CITATION}

Kibor, Joy, and Joshua Tumuti. 2020. "Information and Communications Technology Integration and Performance of Tertiary Institutions in Nairobi County, Kenya." East African Journal of Information Technology 2 (1), 1-7. https://doi.org/10.37284/eajit.2.1.119.

\section{HARVARD CITATION}

Kibor, J. and Tumuti, J. (2020) "Information and Communications Technology Integration and Performance of Tertiary Institutions in Nairobi County, Kenya," East African Journal of Information Technology, 2(1), pp. 1-7. doi: 10.37284/eajit.2.1.119. 


\section{IEEE CITATION}

J. Kibor and J. Tumuti, "Information and Communications Technology Integration and Performance of Tertiary Institutions in Nairobi County, Kenya,” EAJIT, vol. 2, no. 1, pp. 1-7, Mar. 2020.

\section{MLA CITATION}

Kibor, Jerop and Joshua, Tumuti. "Information and Communications Technology Integration and Performance of Tertiary Institutions in Nairobi County, Kenya." East African Journal of Information Technology, Vol. 2, no. 1, Mar. 2020, pp. 1-7, doi:10.37284/eajit.2.1.119.

\section{INTRODUCTION}

Advancement in information and communication technology continues to make an impact on higher education. According to Venkatesh et al. (2016), higher education institutions continue to invest significantly in ICTs that meet the technical pedagogical needs of learners and instructors. Indeed, these technologies result in significant outcomes in productivity, growth, competitiveness, and expansion of education institutions (Karamti, 2016). Globally, higher education institutions continue to embrace the use of ICT to enhance the learner's experiences. In the United States and Spain, the integration has extended to the use of social media platforms such as Twitter in learning activities (Tur et al., 2017). Moreover, instructors are increasingly encouraged to integrate ICTs in instructional practices due to the potential of technology to transform traditional education systems. Technology has become an important aspect of people's lives, and its integration in education is inevitable (Mirzajani et al., 2015).

In Kenya, tertiary institutions such as colleges and universities continue to integrate ICT in education. According to Kosgey and Sang (2012), ICTs have been integrated by tertiary institutions in the form of integrated e-learning and distance learning programs. The integration is facilitated by ICT infrastructure and ICT proficiency. Tertiary institutions in Kenya have integrated ICTs infrastructures such as hardware, software, and networks to support different learning activities. Moreover, the effectiveness of ICT infrastructure is also dependent on ICT proficiency. Stair and Reynolds (2015), asserts that ICT proficiency is the most critical aspect of ICT integration. Learners and instructors must be equipped with skills to enable them to use the ICT infrastructure effectively. The purpose of this research paper is to look at how ICT affects the performance of tertiary institutions. Specifically, the study seeks to establish how ICT infrastructure and ICT proficiency contribute to the performance of tertiary institutions in Nairobi County, Kenya.

In the quest to enhance effective teaching and learning in educational institutions in Kenya, the Government, through National ICT Policy on Education embarked on policies ranging from the provision of affordable ICT infrastructures to schools, facilitation of sharing of ICT resources in school, promotion and facilitation of training of teachers and school managers. This was to aid the integration of ICT through in-service courses (GoK, 2006). The policy birthed connection of over 3000 rural schools with electricity, provision of computers to over 800 schools, establishment Kenya Institute of Education to provide leadership in implementation of ICT in schools, and partnership with both private and public organisations in support of ICT integration in schools (GoK, 2006). However, despite government efforts, schools in Kenya have not effectively adopted ICT to support learning, teaching, and management as intended (Manduku, Kosgey, \& Sang, 2012). Furthermore, ICT policy on education of 2006 has not been effectively implemented as intended, as evidence abounds that other countries have reported over $41 \%$ integration of ICT in schools but the ratio is comparatively low in Kenya (Mingaine, 2013). There is, therefore, need for examination of factors determining integration and usage of ICT on the performance of tertiary institutions in Kenya.

\section{LITERATURE REVIEW}

The use of ICT in higher learning has been a subject of interest for various researchers at the local and global level. A key cause of many developing nations regarding ICT integration and usage in tertiary institution is lack of qualified and skilled IT professionals to effectively harness the benefits of 
ICT for schools. There is a need for sustained investments in ICT programmes that aim at enhancing instructors training to create a new learning environment. The importance of instructors in the implementation and use of ICT is very important because they are at the centre of curriculum implementation and innovation at the institution level. There is a need to invest in ICT training for instructors and other facilitators to enhance the degree of competence, and positive attitudinal behaviour.

Alam and Noor (2009) investigated the factors that influence the integration and usage of ICT by firms in Malaysia. The relationship between factors such as cost, perceived benefits, ICT knowledge, and external pressure as well as government support were all examined and the findings from the data analysed showed that these factors except cost and external pressure significantly influenced integration and usage of ICT. The study impactful because it identified factors that can enhance the integration and usage of ICT, however, this present study deviated from the findings by investigating the relationship between the integration of ICT and possible performance outcomes in an institution.

Numprasertchai and Poovarawan (2008) examined how universities can use ICT based knowledge management system to enhance the performance of students. In a case study of the Kasetsart University in Thailand, the study revealed that the adoption of ICT knowledge management systems enhances students' performance in aspects such as research results and innovation. The findings of this study support the hypothesis that the use of ICTs can enhance student performance in tertiary institutions. Additionally, Mothibi (2015) conducted a meta-analysis to determine how elearning platforms affect the academic achievement of students in South Africa higher learning institutions. The findings indicate that the use of ICT results in higher student achievement especially in the e-learning platforms. Indeed, Gyamfi and Gyaase (2015) also established that the use of ICT led to higher student performance in universities. From the study, it was revealed that lecturers noted an increase in student performance, engagement to each other, as well as participation in class due to the use of ICTs.

Mingaine (2013) investigated the skill challenges in the integration and use of ICT in public school in Kenya. The study was carried out to 105 respondents using descriptive and inferential statistics, after collecting the data it was analysed and the findings showed that there was a limited supply of instructors in Kenya in respect to integration and use of ICT. The study was able to identify the instructor's skill as significant to ICT integration; however, the significance of such skill to performance outcomes need to be investigated. Kipsoi, Changach and Sang (2012) investigated the challenges facing the integration of Information Communication Technology (ICT) in tertiary institutions in Kenya. The study was exploratory in nature and it identified that for ICT to contribute to various segments and sectors in education performance, ICT must be dynamic, cost-effective, adaptable and differentiated. The uptake and usage of ICT in schools needs to be trained in structures and visionary school leadership (Higgins \& Moseley, 2011). It is important for teachers, school leaders and facilitators to be acquainted with the prospective of ICT for facilitating learning and teaching in the school. A study by Kandiri, (2012) on ICT access and usage in Kenyan schools reported that the number of the absorbed IT instructors in Kenyan tertiary institutions was relatively small compared to the number of IT graduates from universities and other tertiary institutions across Kenya. Overall, the findings of each of these studies support the assumption that the use of ICT can result in better student performance in tertiary institutions.

\section{CONCEPTUAL FRAMEWORK}

The independent variables in the conceptual framework are given by ICT proficiency and ICT infrastructure. The dependent variable is student performance. The study makes an assumption that increase use of ICT infrastructures such as computers and e-learning platforms together with improved ICT proficiency of lecturers can improve the performance of students in tertiary institutions in Nairobi County. 
Figure 1: Conceptual Framework

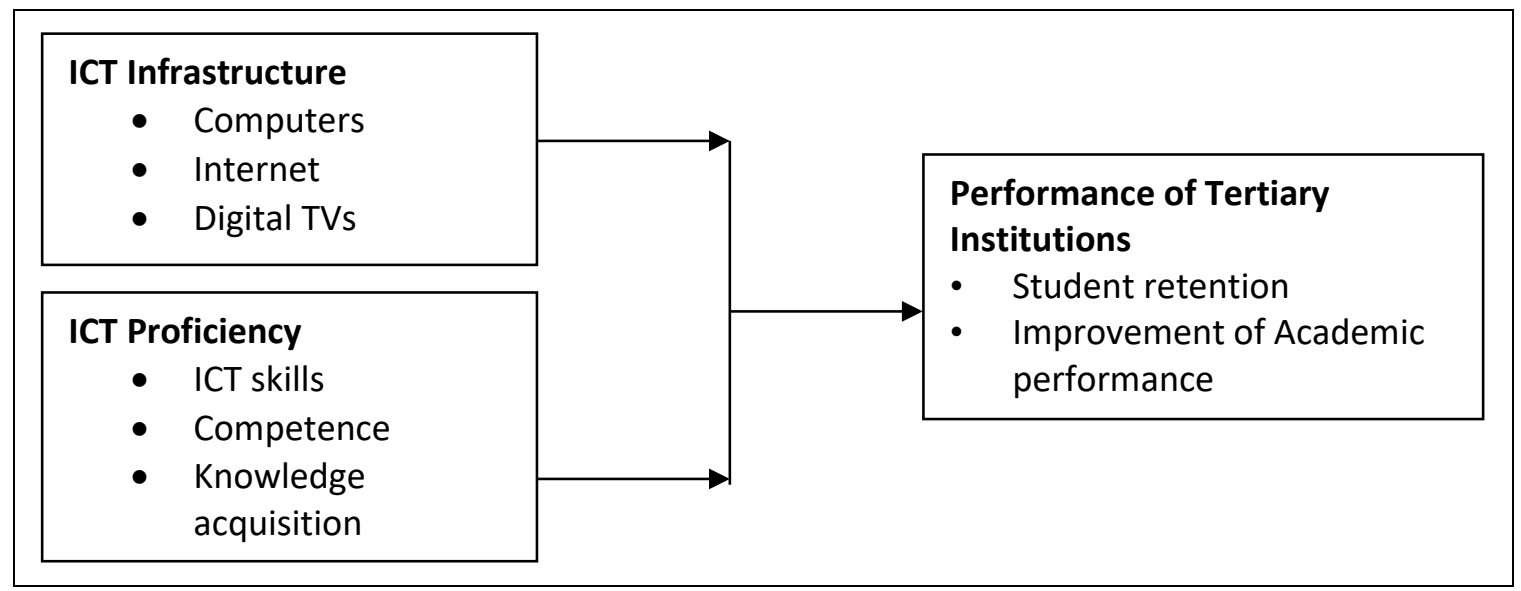

Source: Researcher's Conceptualization (2020)

\section{METHODOLOGY}

The study employed a descriptive cross-sectional survey design to investigate the adaptation of ICT on performance among tertiary institutions in Nairobi County. The population in this study was tertiary institutions in Nairobi County. The tertiary institutions were preferred because of evidence in the increase in ICT integration among tertiary institutions in Nairobi County. The actual respondents comprise of ICT specialists from the tertiary institutions. The current number of tertiary institutions in Nairobi County stands at 149 (Government of Kenya, 2013). A simple random sampling approach was used to obtain a sample of 60 respondents for the study. Moreover, data were collected through that use of self-administered questionnaires that were distributed to the respondents. The questionnaires used a 5-point Likert's scale ranging from $5=$ strongly agree to $1=$ strongly disagree. The descriptive statistics that were appropriate were the mean and standard deviation. The study computed the mean score per variable and the accompanying measure of the dispersion of standard deviation. Moreover, data was analysed through a multiple regression model to estimate the relationship between ICT infrastructure, proficiency and performance of tertiary institutions. Descriptive and inferential statistics were used for data analysis.

\section{RESULTS AND DISCUSSION}

\section{ICT Infrastructure on Performance of Tertiary Institutions}

On ICT Infrastructure and Performance, the respondents agreed $(\mathrm{M}=4.34, \mathrm{SD}=0.757)$ that $\mathrm{ICT}$ influences the performance of tertiary institution (See Table 1). The respondents also agreed that desktops are the widely used ICT hardware in your school ( $\mathrm{M}=4.26, \mathrm{SD}=0.978)$. Regarding whether laptops are used to make learning more interactive and motivating $(\mathrm{M}=4.02, \mathrm{SD}=0.672)$ agreed. In regard to if the acquisition of ICT software has aided and enhanced academic activities in your school $(\mathrm{M}=4.44, \mathrm{SD}=0.700)$ of the respondents agreed. The respondents also strongly agreed that ICT infrastructure (computers) enhances student teaching $(M=4.6, S D=0.629)$. On whether serverbased databases supported academic and management functions in the school $(\mathrm{M}=4.28$, $\mathrm{SD}=0.797$ ) respondents agreed. And finally, the respondents further agreed that Uninterrupted network encourages and motivates the users of ICT $(M=4.49, S D=0.768)$. These research findings were in line with a study done by Mahmood et al. (2011) who reported that Students agreed that ICT is suitable for classroom teaching at a higher level and ICT enhances communication ability in students. 
Table 1: Frequency Table and Mean for ICT Infrastructure on Performance

\begin{tabular}{lll}
\hline Statement & Mean & Std. Dev \\
\hline Desktops are the widely used ICT hardware in your school. & 4.26 & 0.978 \\
Laptops are used to make learning more interactive and motivating. & 4.02 & 0.672 \\
Acquisition of ICT software has aided and enhanced academic activities in & 4.44 & 0.700 \\
your school. & & \\
Server-based databases now support academic and management functions in & 4.28 & 0.797 \\
your school. & 4.6 & 0.629 \\
ICT infrastructure (computers) enhances student teaching. & 4.49 & 0.768 \\
Uninterrupted network encourages and motivates the users of ICT & 4.34 & 0.757 \\
\hline Average & & \\
\hline
\end{tabular}

On ICT proficiency and Performance, the study established that overall, the respondents agreed on the effect of ICT proficiency on performance in tertiary institutions as evidenced by $(M=4.19, S D=$ 0.756) (See Table 2). The respondents agreed that ICT training enhances the students' technical skills and content knowledge $(\mathrm{M}=4.21, \quad \mathrm{SD}=0.600)$. Additionally, ICT helps to build confidence and promote classroom management techniques $(\mathrm{M}=4.14, \mathrm{SD}=0.710)$. Moreover, the respondents agreed that available software programmes have enhanced the learners' knowledge in the process of discharging his duties $(M=4.37, S D=0.757)$. Opira (2010) noted that computer user-ability skills influence the learning of students and lecturers with such skills were seen to be more comfortable in their application of the various computer programs. The respondents also agreed that reading and writing skills have been improved due to ICT integration ( $\mathrm{M}=3.98$, $\mathrm{SD}=0.938$ ). Further, the respondents agreed that confidence in the student's ability to do things right was due to use of the skills developed via ICT $(\mathrm{M}=4.23, \mathrm{SD}=0.751)$ and finally the respondents agreed that the positive attitude towards my learner was based on the ICT knowledge possessed by the learner $(\mathrm{M}=$ 4.23, $\mathrm{SD}=\quad$ 0.782). Zhu (2003) similarly noted that ICT helps teachers and learners to communicate and collaborate without boundaries, make learners autonomous and allow teachers to bring the whole world into classroom activities.

Table 2: Frequency Table and Mean for ICT Proficiency in Performance

\begin{tabular}{lll}
\hline Statement & Mean & SD \\
\hline ICT training enhances my technical skills and content knowledge. & 4.21 & 0.600 \\
ICT helps to build confidence and promote classroom management techniques. & 4.14 & 0.710 \\
Available software programmes have enhanced my knowledge in the process of & 4.37 & 0.757 \\
discharging my duties. & 3.98 & 0.938 \\
My reading and writing skills have been improved via ICT. & 4.23 & 0.751 \\
I have confidence in my ability to do things right because of the skills developed & & \\
via ICT. & & 0.782 \\
I have assumed a positive attitude towards my work based on the knowledge I & 4.23 & \\
have in ICT. & 4.19 & 0.756 \\
Average &
\end{tabular}

The direct relationship between the adoption of ICT and the performance of tertiary institution was tested using multiple regression method. As shown in Table 3, the coefficient of correlation $(\mathrm{R}=.603)$ indicated a strong prediction of the relationship between the adoption of ICT and the performance 
of tertiary learning institution. The coefficient of determination $\left(\mathrm{R}^{2}=0.531\right)$ indicated that the composite construct of adoption of ICT (independent variable) explained $53.1 \%$ variation in the performance of tertiary learning institution in
Kenya (dependent variable). The remaining percentage of $46.9 \%$ variation in the dependent variable would be explained by other variables outside the scope of this study.

Table 3: Regression Results of Direct Relationship

\begin{tabular}{llll}
\hline Goodness of fit & Test Statistics & p-value & \\
\hline $\mathrm{R}$ & 0.603 & & \\
R-squared & 0.531 & \\
Adjusted R-squared & 0.452 & \\
F-value & 1.440 & 0.000 & \\
$\begin{array}{l}\text { Dependent Construct } \quad \text { =Performance } \quad \text { of } \\
\text { Institutions }\end{array}$ & & & \\
& & & \\
ICT infrastructure & Coefficients & t-statistics & p-value \\
ICT proficiency & 0.085 & 1.464 & 0.046 \\
Constant & 0.252 & 1.363 & 0.031 \\
Note: p is statistically significant at 5\% & 2.264 & 2.368 & 0.023 \\
\hline
\end{tabular}

The F-value $(1.440, \mathrm{p}=0.00)$ was significant and therefore indicated a fit between the data and the model of this study. As also shown in Table 3, the results of the hypothesized relationships showed that both ICT infrastructure and proficiency were significant and positively related to the performance of tertiary institutions in Kenya. At $t=$ $1.464, \mathrm{p}=0.046$, the hypothesis of no significant effect of ICT infrastructure on the performance of tertiary institution was not accepted, and therefore ICT infrastructure has a significant effect on the performance of the tertiary institution in Kenya. At $\mathrm{t}=1.363, \mathrm{p}=0.031$, the null hypothesis of significant effect of ICT proficiency on the performance of tertiary institution was not accepted. Therefore, thus indicated that ICT proficiency had a significant effect on the performance of tertiary institutions in Kenya. The regression equation for the model is therefore expressed as performance of tertiary institution $=$ $2.264+0.085$ ICT infrastructure +0.252 ICT proficiency. The regression equation, therefore, indicated that with ICT proficiency holding on constant, a unit increase in ICT infrastructure will lead to 0.085 increases in performance of the tertiary institution in Kenya. Moreover, a unit increase in ICT proficiency, holding ICT infrastructure constant, will lead to 0.252 increases in performance of the tertiary institution in Kenya.
The study established a significant relationship with a correlation coefficient indicating a strong relationship between the study variables. Majority of the respondents agreed that uninterrupted network encourages and motivates the users of ICT. Acquisition of ICT software was also found to have aided and enhanced academic activities in the schools. On ICT proficiency, majority of the respondents agreed that available software programmes enhanced knowledge in the process of discharging duties.

\section{CONCLUSION}

Based on the findings of the study, there is need for institutions to invest more in ICT infrastructure and related technology as means of creating more accessibility and the presence of the facilities such as server-based databases and laptops to make learning more interactive and motivating. ICT infrastructure combined with ICT proficiency results in better student performance in tertiary institutions. Notably, tertiary institutions in Nairobi County have invested in ICT infrastructures such as computers and e-learning platforms, and this has led to significant improvement in student performance. Moreover, continued training of instructors and learners on how to utilize the ICT infrastructure effectively in order to increases ICT 
proficiency that results in enhanced student performance. Therefore, it is ideal to ensure that tertiary institution should continue increasing the use of ICT to ensure effective returns in improved student performance.

\section{REFERENCES}

Gyamfi, S. A., \& Gyaase, P. O. (2017). Virtualization of University Education: The Impact of ICT-Mediated Learning Environment on Students' Performance. International Journal of E-Services and Mobile Applications (IJESMA), 9(4), 24-40.

Karamti, C. (2016). Measuring the impact of ICTs on academic performance: Evidence from higher education in Tunisia. Journal of Research on Technology in Education, 48(4), 322-337.

Mahmood, A., Bokhari, N. H., \& Naqvi, F. (2011). Effects of the use of ICT: students' perception at higher education level. Elixir Social Studies, $38,4218-4221$.

Manduku, J. G., Kosgey, A. K., \& Sang, H. (2012). Adoption and use of ICT in enhancing management of public secondary schools: A survey of Kesses zone secondary schools in Wareng District of Uasin Gishu County, Kenya.

Mingaine, L. (2013). Skill challenges in integration and use of ICT in public secondary schools, Kenya. International Journal of Humanities and Social Science, 3(13), 61-72.

Mirzajani, H., Mahmud, R., Fauzi Mohd Ayub, A., \& Wong, S. L. (2016). Teachers' acceptance of ICT and its integration in the classroom. Quality Assurance in Education, 24(1), 26-40.

Mothibi, G. (2015). A Meta-Analysis of the Relationship between E-Learning and Students' Academic Achievement in Higher Education. Journal of Education and Practice, 6(9), 6-9.

Numprasertchai, S., \& Poovarawan, Y. (2008). Improving university performance through ICT based knowledge management system.
International Journal of Innovation and Technology Management, 5(02), 167-178.

Opira, G. (2010). Effects of information and communication technology on students' learning: a case of Gulu university (Doctoral dissertation, Makerere University).

Takalani, T. (2008). Barriers to e-learning amongst postgraduate black students in higher education in South Africa. Master of Philosophy Thesis. Stellenbosch, SA: Stellenbosch University.

Tur, G., Marín, V. I., \& Carpenter, J. (2017). Using Twitter in higher education in Spain and the USA. Comunicar: Media Education Research Journal, 25(51), 19-27.

Venkatesh, V., Rabah, J., Fusaro, M., Couture, A., Varela, W., \& Alexander, K. (2016). Factors impacting university instructors' and students' perceptions of course effectiveness and technology integration in the age of web 2.0. McGill Journal of Education/Revue des sciences de l'éducation de McGill, 51(1), 533561.

Zhu, Z. T. (2003). Educational Informatization and the transforms of educational cultures. Journal of Global Chinese Society of Computers in Education, 1(3), 12-23. 